\title{
Modification of poly(methyl methacrylate) microchannels for highly efficient and reproducible electrophoretic separations of double-stranded DNA
}

\author{
Yang-Wei Lin, Huan-Tsung Chang* \\ Department of Chemistry, National Taiwan University, 1, Section 4, Roosevelt Road, Taipei, Taiwan, ROC
}

\begin{abstract}
This paper deals with dynamic coating of the microchannels fabricated on poly(methyl methacrylate) (PMMA) chips and DNA separation by microchip electrophoresis (MCE). After testing a number of polymers, including 2-hydroxyethyl cellulose, hydroxypropylmethyl cellulose, different sizes of poly(ethylene oxide) (PEO), and poly(vinyl pyrrolidone) (PVP), we found that coating of the PMMA microchannels with $\operatorname{PEO}\left(M_{\mathrm{r}}=6.0 \times 10^{5} \mathrm{~g} / \mathrm{mol}\right)$ on the first layer is essential to minimize the interaction of DNA with PMMA surface. To achieve high efficiency, multilayer coating of PMMA chips with PEO, PVP, and PEO containing gold nanoparticles [PEO(GNP)] is important. A 2(PEO-PVP)-PEO(GNP) PMMA chip, which was repeatedly coated with $1.0 \%$ PEO and 5.0\% PVP twice, and then coated with $0.75 \%$ $\mathrm{PEO}\left(\mathrm{GNP}\right.$ ) each for $30 \mathrm{~min}$, provided a high efficiency (up to $1.7 \times 10^{6}$ plates/m) for the separation of DNA markers V (pBR 322/HaeIII digest) and VI (pBR 328/BglI digest and pBR 328/HinfI digest) when using 0.75\% PEO(GNP). With such a high efficiency, we demonstrated the separation of hsp65 gene fragments of Mycobacterium HaeIII digests by MCE within $90 \mathrm{~s}$. The advantages of this approach to DNA analysis include ease of filling the microchannel with $0.75 \%$ PEO(GNP), rapidity, and reproducibility.
\end{abstract}

(C) 2004 Elsevier B.V. All rights reserved.

Keywords: DNA separation; Dynamic coating; Gold nanoparticles; Microfluidic devices; Poly(ethylene oxide); Poly(methyl methacrylate)

\section{Introduction}

Rapid, efficient, and sensitive separation methods are highly demanded after the post-genome era, in which diagnostic applications including genetic mutation detection and characterization of polymorphisms will continue playing an important role [1-5]. Microchip capillary electrophoresis (MCE) using polymer solutions has shown powerful for DNA analysis because of its advantages of high resolving power, rapidity, minute sample requirement, and ease of integration [6-9]. Polymer solutions are advantageous over cross-linked gels, including relatively low viscosity, ease of preparation, and flexibility. Common polymer solutions used for DNA sequencing, forensic applications, and the analysis of polymerase chain reaction (PCR) products in MCE are prepared from linear polymers, including cellulose and its derivatives,

\footnotetext{
* Corresponding author. Tel.: +8862 23621963; fax: +886223621963.

E-mail address: changht@ntu.edu.tw (H.-T. Chang).
}

linear poly(acrylamide) (LPA), poly(ethylene oxide) (PEO), or poly(vinyl pyrrolidone) (PVP) [8-12].

Microchips fabricated in a variety of substrates, including glass, quartz, and plastics, have been used for electrophoretic separations of DNA [13-18]. Polymer substrates such as polycarbonate [17] and poly(methyl methacrylate) (PMMA) [18] are particularly interesting because they offer a greater potential for making disposable devices on a cost-effective basis by printing, laser ablation, and plasma etching [18-21]. However, DNA tends to adsorb on the surface of the plastic substrates, leading to loss of resolution and variation of electroosmotic flow (EOF). Thus, elimination of EOF and prevention of analyte adsorption are important for achieving highly efficient and reproducible DNA separation by MCE [22]. To achieve this goal, chemicals or polymers have been used to modify the PMMA wall surface either through covalently bonding or through physically adsorbed (dynamic) coating [23,24]. Because of its simplicity, possibility for automatic coating and regeneration, and access to a priori knowledge of polymer physical properties, dynamic coating has 
become more popular. Cellulose derivatives such as hydroxypropylmethyl cellulose-50 (HPMC-50) have been shown effective to minimize DNA interaction with the channel wall in PMMA chips [25]. Unfortunately, we have found that the separation of DNA markers V (pBR 322/HaeIII digest) and VI (pBR 328/BglI digest and pBR 328/HinfI digest) was not quite successful (several unresolved peaks for the DNA fragments less than $1033 \mathrm{bp}$ ) using the suggested conditions. Further increasing the concentrations of HPMC-50 and/or polyhydroxy additives (mannitol, glucose, and glycerol) did not improve resolution, but deteriorated it, probably due to poor solubility of HPMC-50 and changes in the morphology of the entangled solutions at high concentrations (with increasing HPMC-50 concentration, the color changed from transparent to pale yellow and eventually turns to opaque at $4.0 \%$ ).

Based on our own experiences, among a number of polymers commonly used to minimize DNA adsorption, we have found that PEO and/or PVP dynamic coating of PMMA microchannels is acceptable when conducting the separation using PEO solutions containing gold nanoparticles (GNPs) [24]. This is partially because GNPs are more stable in the two polymer solutions [26] when compared to others such as cellulose derivatives and LPA. Using PVP-PEO-GNP PMMA chips, we demonstrated the separation of DNA markers $\mathrm{V}$ and VI ranging in size from 8 to 2176 bp by MCE [24]. With a comparable resolving power to that obtained by $\mathrm{CE}$ using a 40-cm long capillary filled with $0.2 \%$ PEO(GNP) (viscosity $=15 \mathrm{cP})$ [27], $1.5 \%$ PEO(GNPs) was required when using a PVP-PEO-GNP PMMA chip with a 4-cm long separation channel. Hereafter, PEO(GNP) refers to PEO solutions containing GNPs. A longer separation time (18 min versus $5 \mathrm{~min}$ ) shows a drawback of MCE when using the PVP-PEO-GNP PMMA chip. Since the diffusion coefficient of DNA and dispersion are both smaller in a high-viscosity solution, we concluded that the loss of efficiency is due to the interaction of DNA with the PVP-PEO-GNP PMMA chip as a result of poor coating.

It needs high pressure to fill and flush the microchannel when using a high viscosity of $\mathrm{PEO}(\mathrm{GNP})$ solution like $1.5 \%$ $\mathrm{PEO}(\mathrm{GNP})$. The aim of this study is to develop an effective way to coat the PMMA microchannel surface in order to conduct DNA separation using low-viscosity PEO(GNP) solutions. Based on our previous results [12,24], we fabricated multilayer-coated PMMA chips. In this paper, we demonstrated reproducible, high-resolving, and high-speed DNA separations using a 2-(PEO-PVP)-PEO(GNP) PMMA chip with a $75 \mu \mathrm{m}$ channel filled with $0.75 \%$ PEO containing 56nm GNPs (viscosity $=158 \mathrm{cP}$ ).

\section{Materials and methods}

\subsection{Chemicals}

All polymer solutions used for dynamic coating of the PMMA chips and plates were prepared from linear poly- mers purchased from Aldrich (Milwaukee, WI, USA). The molecular weights $(\mathrm{g} / \mathrm{mol})$ are 1300000 and 250000 for HEC, 1000000 for HPC, $8000000,4000000,2000000$, and 600000 for PEO, and 1300000 for PVP. Ethidium bromide (EtBr) was obtained from Molecular Probes (Eugene, OR, USA). Sodium hydroxide was used to adjust the $\mathrm{pH}$ value of $500 \mathrm{mM}$ glycine solution to 9.1 . The 56-nm GNPs were synthesized according to a literature procedure [28]. The concentration of thus made GNPs is denoted by $1 X$ (about $4.93 \times 10^{-11} \mathrm{M}$ ) and their size is $55.6 \pm 1.2 \mathrm{~nm}$ confirmed by UV-vis absorption measurements and TEM images [29]. Glycine buffer $(50 \mathrm{mM}$, pH 9.1) containing $0.3 X$ GNP was prepared by mixing $15 \mathrm{~mL}$ of thus prepared 56-nm GNPs (a weakly acidic solution containing less than $0.1 \mathrm{mM}$ citric acid), $5 \mathrm{~mL}$ glycine $(500 \mathrm{mM}, \mathrm{pH} 9.1)$, and $30 \mathrm{~mL}$ deionized water. Different amounts of $\operatorname{PEO}\left(M_{\mathrm{r}}=8.0 \times 10^{6} \mathrm{~g} / \mathrm{mol}\right)$ were gradually added to the above-prepared solutions while stirring in a water bath at $85-90^{\circ} \mathrm{C}$. After additions were completed, the suspensions were stirred for at least one more hour. Finally, polymer solutions were degassed with a vacuum system in an ultrasonic tank. The viscosity of the prepared $0.75 \%$ PEO solutions was $158 \pm 2 \mathrm{cP}$. For simplicity, we used $\operatorname{HEC}\left(M_{\mathrm{r}}\right), M_{\mathrm{r}}=2.5 \times 10^{5}$ and $1.3 \times 10^{6} \mathrm{~g} / \mathrm{mol}$ as well as $\operatorname{PEO}\left(M_{\mathrm{r}}\right), M_{\mathrm{r}}=0.6 \times 10^{6}, 2.0 \times 10^{6}, 4.0 \times$ $10^{6}$, and $8.0 \times 10^{6} \mathrm{~g} / \mathrm{mol}$ to represent polymer solutions prepared form different sizes of polymers. Polymer solutions used for coating the microchannels of PMMA chips were prepared in a similar manner. $\Phi$ X 174 RF DNA-HaeIII digest was purchased from Pharmacia Biotech (Uppsala, Sweden). DNA markers V (pBR 322/HaeIII digest) and VI (pBR 328/BglI digest and pBR 328/HinfI digest) were purchased from Boehringer Mannheim (Mannheim, Germany). Equal volumes of DNA markers V and VI were mixed and used in this study.

\subsection{Instrumentation}

The separation of DNA was performed on a laboratory made MCE system in an epi-fluorescence configuration as shown in Fig. 1. In the system, a $4.0 \mathrm{~mW} \mathrm{He}-\mathrm{Ne}$ laser at $543.6 \mathrm{~nm}$ from Uniphase (1676, Mantence, CA, USA) was used to excite ethidium bromide intercalated DNA complexes and two laboratory-made high-voltage power supplies (C4710-40, Hamamatsu Photonics, Shizuoka-Ken, Japan) was used to drive electrophoresis. The entire detection system was enclosed in a black box with a high-voltage interlock. The light was reflected from a dichroic mirror (XF2017, Omega Optical, VT, USA) and focused with a $20 \times$ objective (numerical aperture $=0.25$ ). The dichroic mirror, a laboratory-made slit ( $2 \mathrm{~mm}$ in diameter), and a RG 610 cut-off filter were used to block scattered light before the emitted light that was focused with the same $20 \times$ objective reached the photomultiplier tube (R928, Hamamatsu Photonics). The amplified currents were transferred directly through a $10 \mathrm{k} \Omega$ resistor to a 24-bit LabView I/O interface card at $10 \mathrm{~Hz}(6024 \mathrm{E}$, National Instruments, USA) that was 


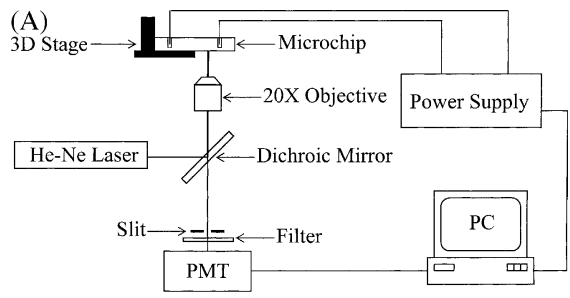

(B)

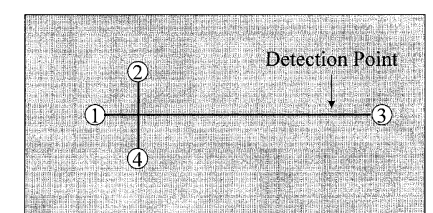

\begin{tabular}{lcc}
\hline \multicolumn{1}{c}{ Reservoir } & Injection Voltage (kV) & Separation Voltage (kV) \\
\hline T(Buffer) & 0 & 0 \\
2(Sample outlet) & 0.60 & 0.25 \\
3(Buffer) & 0 & 0.75 \\
4 (Sample inlet) & 0 & 0.25 \\
\hline
\end{tabular}

Fig. 1. Schematic diagrams of a MCE separation and detection system (A) and a representative PMMA microchip (B). Representative injection and separation voltages were listed in the table under (B).

stored in a personal computer. A LabView program was used for voltage control and data acquisition. A viscometer (DV-E, Brookfield Engineering Labs., MA, USA) was used to conduct the viscosity measurements of $\operatorname{PEO}(8.0 \times$ $\left.10^{6} \mathrm{~g} / \mathrm{mol}\right)$ and $\mathrm{PEO}(\mathrm{GNP})$ solutions at $25^{\circ} \mathrm{C}$. The UV-vis spectra of the coated PMMA plates were conducted using a UV-vis spectrometer (Cintra 10e, GBC Victoria, Australia).

\subsection{Microfabrication}

The wires (75 and $50 \mu \mathrm{m}$ in diameter) used to fabricate microchannels according to a wire imprinting method [30] were obtained from Omega Engineering (Stanford, CT, USA). A piece of 40.0-mm wire and a PMMA plastic plate clamped between two clean glass slides were placed in an oven at $110^{\circ} \mathrm{C}$ for $10 \mathrm{~min}$. Then, the assembly was put aside at room temperature in the course of forming the microchannel (separation channel). Another piece of wire was used to make a 10.0-mm long channel orthogonal to the separation channel on another PMMA plate in a similar manner. Prior to sealing, four holes of $3.0 \mathrm{~mm}$ in diameter used as buffer and sample reservoirs were drilled on the PMMA plate with a 10.0-mm long channel with a power screw driver. The two pieces of PMMA plastics were then sealed in the oven at $110^{\circ} \mathrm{C}$ for $8 \mathrm{~min}$. The total and effective lengths of the separation channel with the size of $75 \mu \mathrm{m} \times 75 \mu \mathrm{m}$ are 40.0 and $30.0 \mathrm{~mm}$, respectively. The distances from the cross-section to reservoir 1 (buffer), reservoir 3 (buffer), reservoir 2 (sample waste), and reservoir 4 (sample) are 5.0, 35, 5.0, and $5.0 \mathrm{~mm}$, respectively.

\subsection{Dynamic coating}

The microchannels were cleaned with fresh water for 10 min prior to dynamic coating. PMMA chips, named $X$ -
(PEO-PVP)-PEO(GNP) were made and tested for DNA separations, in which $X=1-10$. The coating procedures for $X$ (PEO-PVP)-PEO(GNP) PMMA chips are: the channel was equilibrated with $1.0 \% \operatorname{PEO}\left(6.0 \times 10^{5} \mathrm{~g} / \mathrm{mol}\right)$ at room temperature for $30 \mathrm{~min}$; PEO was flushed out with water and then the channel was filled and equilibrated with PVP at room temperature for $30 \mathrm{~min}$; PVP was flushed out with water; the sequence was repeated to obtain the desired number of layers $(X)$; finally, the channel was subjected to final coating with $0.75 \% \mathrm{PEO}(\mathrm{GNP})$ for $30 \mathrm{~min}$. Owing to a difficulty of monitoring the coating on the PMMA channel surface using a commercial spectrometer, we used PMMA plates that were coated in a similar manner.

\subsection{DNA extraction and PCR products}

A loop of mycobacteria grown on solid medium was suspended in $500 \mu \mathrm{L}$ of TE buffer $(10 \mathrm{mM}$ Tris, $1 \mathrm{mM}$ EDTA, pH 8) and inactivated by boiling for $30 \mathrm{~min}$. Template DNA was extracted by Puregene DNA purification kit (Gentra Systems, MN, USA) according to the manufacture's instructions. A pair of unlabeled primers Tb11 (5'-ACCAACGATGGTGTGTCCAT) and Tb12 (5'CTTGTCGAACCGCATACCCT) were used in PCR to amplify the $h$ sp 65 gene which was a 439-bp fragment between positions 398 and 836 as published [31]. PCR mixtures contained $10 \mathrm{mM}$ Tris- $\mathrm{HCl}(\mathrm{pH} 8.3), 50 \mathrm{mM} \mathrm{KCl}, 1.5 \mathrm{mM}$ $\mathrm{MgCl}_{2}, 10 \%$ glycerol, $0.4 \mu \mathrm{M}$ (each) primer, $200 \mu \mathrm{M}$ of each of four dNTPs, 1.25 units of Taq polymerase (Qiagen, Hilden, Germany), and $3 \mu \mathrm{L}$ of the DNA template in a final volume of $50 \mu \mathrm{L}$. Thermocycling of the reaction mixture was performed in a Thermocycler (2700, Applied Biosystem, Foster City, USA) programmed for 35 cycles $\left(60 \mathrm{~s}\right.$ at $94^{\circ} \mathrm{C}, 60 \mathrm{~s}$ at $60{ }^{\circ} \mathrm{C}, 60 \mathrm{~s}$ at $72^{\circ} \mathrm{C}$ ) followed by a 10 -min incubation at $72{ }^{\circ} \mathrm{C}$. The amplified products were then digested with restriction endonuclease HaeIII (New England Biolabs, MA, USA): $10 \mu \mathrm{L}$ of the amplified reaction solution was added to a mixture containing $1 \mu \mathrm{L}$ of enzyme ( 5 units), $5 \mu \mathrm{L}$ of restriction buffer $(10 \times)$, and $34 \mu \mathrm{L}$ of autoclaved distilled water; the mixtures were incubated for $60 \mathrm{~min}$ at $37^{\circ} \mathrm{C}$ for HaeIII digestion.

\subsection{Electrophoretic procedure}

Unless otherwise noted, the injection and separation voltages were applied as addressed further. The DNA samples at the concentrations ranging from 2.5 to $10 \mu \mathrm{g} / \mathrm{mL}$ were electrokinetically injected to the channels $(75 \mu \mathrm{m} \times 75 \mu \mathrm{m})$ from sample reservoir 4 by applying $600 \mathrm{~V}$ at sample waste reservoir 2 for $10 \mathrm{~s}$, while the other three reservoirs were grounding. Sample separation was accomplished by applying $750 \mathrm{~V}$ (electric field strength of $187.5 \mathrm{~V} / \mathrm{cm}$ ) at the analysis reservoir $3,250 \mathrm{~V}$ at sample and sample waste reservoirs 2 and 4, and grounding buffer reservoir 1 (Fig. 1B). When PMMA chips with different sizes of microchannels were used, the separations were conducted at the same electric field strengths. 
After each run, a 50-mL syringe positioned on reservoir 3 was used to suck out the used PEO(GNP); reservoir 1 was filled with fresh PEO(GNP) that was filled to the channel by suction using another 50 -mL syringe positioned on reservoir 3. In this study, PEO(GNP) represents the PEO solution containing 56-nm GNPs.

\section{Results and discussion}

\subsection{Dynamic coating and separation of $\Phi X 174 R F$ DNA-HaeIII digest}

In our previous report [27], we demonstrated highly efficient DNA separation by CE using low-viscosity PEO(GNP) solutions and suggested that the change of the morphology of PEO matrices and effective coating of PVP and/or PEO on the capillary wall in the presence of GNPs are two main contributors for improved resolution. We note that the viscosity of PEO changes less than $0.2 \%$ in the presence of $1 X$ GNPs. However, such low-viscosity PEO(GNP) solutions could not provide a high resolving power for DNA in MCE when using a PVP-PEO-GNP chip, mainly because of poor coating. In order to achieve comparable resolution obtained by $\mathrm{CE}$, $1.5 \% \mathrm{PEO}(\mathrm{GNP})$ solution $(1680 \mathrm{cP})$ was required in MCE. Owing to its high viscosity, it is extremely difficult to fill the sieving matrix to the small PMMA microchannels. It is thus important to minimize DNA adsorption on the PMMA surface, allowing use of low concentrations of PEO(GNP) solutions. To achieve this goal, we tested different coating strategies based on the following facts: (1) the surface coverage is generally more completed with small molecules such as amines and surfactants; (2) multilayer coating provides greater efficiency as a result of weaker interactions between the wall and the migrating analytes because of less access; (3) the stability of GNPs is greater in PVP than in PEO; and (4) the interaction of PMMA with PVP is weaker than that with PEO (our own experience) [22,32-36].

Amines from monoamines (triethylamine, triethanolamine and ethylamine) to oligoamines (spermidine, spermine and tetraethylenepentamine) have been used to minimize analyte adsorption [32,37], but they are not suitable in this study because they significantly induce aggregation of GNPs. We then turned our strategy to coat the PMMA chips using different polymers, including PEO with the $M_{\mathrm{r}}$ values of $0.6-8.0 \times 10^{6} \mathrm{~g} / \mathrm{mol}$, PVP with the $M_{\mathrm{r}}$ values of $1.3 \times$ $10^{6} \mathrm{~g} / \mathrm{mol}$, HEC with the $M_{\mathrm{r}}$ values of $0.25 \times 10^{6}$ and $1.3 \times$ $10^{6} \mathrm{~g} / \mathrm{mol}$, and HPC with the $M_{\mathrm{r}}$ values of $1.0 \times 10^{6} \mathrm{~g} / \mathrm{mol}$. When conducting the separation of $\Phi$ X 174 RF DNA-HaeIII digest using $0.75 \%$ PEO(GNP), the chip firstly coated with $5.0 \%$ PVP and then with $0.75 \%$ PEO(GNP) provided some broad peaks as shown in Fig. 2A. Using the same separation condition, only one broad peak with poor irreproducibility was detected when using HEC or HPC to coat the PMMA chips before being subjected to coating with PEO(GNP). The results reveal that coating of PMMA chips with these polymers is ineffective. Fig. 2B shows that a chip coated with $1.0 \% \operatorname{PEO}\left(6.0 \times 10^{5} \mathrm{~g} / \mathrm{mol}\right)$ and then $0.75 \% \operatorname{PEO}(\mathrm{GNP})$ provided an acceptable resolution, with total resolved peaks of 11 in $4 \mathrm{~min}$. We note that there were only 1,2, and 4 peaks obtained when using $\operatorname{PEO}\left(8.0 \times 10^{6} \mathrm{~g} / \mathrm{mol}\right), \operatorname{PEO}(4.0 \times$ $\left.10^{6} \mathrm{~g} / \mathrm{mol}\right)$, and $\operatorname{PEO}\left(2.0 \times 10^{6} \mathrm{~g} / \mathrm{mol}\right)$ instead of PEO $(6.0$ $\times 10^{5} \mathrm{~g} / \mathrm{mol}$ ) to coat the PMMA chips, respectively. The results reveal that coating of PMMA chips with small PEO is definitely advantageous over larger ones and PVP. Fig. 2C shows that the separation of the same DNA sample using a PEO-PVP-PEO(GNP) PMMA chip, with the relative standard deviations $(n=3)$ less than $1.3 \%$ and $3.3 \%$ for migration times and peak areas for all DNA fragments, respectively. The advantage of the PEO-PVP-PEO(GNP) PMMA chip over that of PEO-PEO(GNP) chip is further listed in Table 1; PEO-PVP-PEO(GNP) PMMA chip provided a greater resolving power for the small DNA fragments ( $<603 \mathrm{bp})$. This is mainly because small DNA fragments have less access to the microchannel surface in a PEO-PVP-PEO(GNP) PMMA chip as a result of thicker and more complete coating. A sandwiched PVP layer minimizes direct interactions between two different PEO molecules $\left(M_{\mathrm{r}}=0.6 \times 10^{6}\right.$ and $\left.8.0 \times 10^{6} \mathrm{~g} / \mathrm{mol}\right)$, which ensure the formation of multilayer coating (discussed later). We note that the separation is also faster using the PEO-PVP-PEO(GNP) PMMA chip, mainly because of a smaller EOF (against DNA migration) and weaker interactions of DNA with the channel wall. Since there are ester groups and carboxylic groups in PMMA surface, supported with the existence of small EOF $\left(2.1 \times 10^{-4} \mathrm{~cm}^{2} \mathrm{~s}^{-1} \mathrm{~V}^{-1}\right)$ in $10 \mathrm{mM}$ triethylamonium acetate (pH 7.0) [38], we strongly believe that the suppression of EOF is due to the interactions between PMMA and PEO through hydrogen bonding and hydrophobic patches. Decreases in the surface charge density due likely to the interactions of cationic PVP polymers with anionic PMMA surface and with GNPs should also take account for small EOF mobility. The existence of small EOF toward the anodic end in the presence of PVP is ruled out as suggested in our previous studies [12,39]. Table 1 also presents that $\mathrm{PEO}(\mathrm{GNP})$ provides higher resolving power for DNA than does PEO solution, mainly due to changes in PEO morphology [27].

\subsection{Separation of DNA markers $V$ and $V I$}

Although the PEO-PVP-PEO(GNP) PMMA chip is useful for separating DNA, at least $0.75 \% \mathrm{PEO}(\mathrm{GNP})$ is required, which is higher than $0.2 \% \mathrm{PEO}(\mathrm{GNP})$ used in $\mathrm{CE}$ (fused silica). This suggests that the interaction between the PMMA microchannel wall and DNA still exists. Our reasoning is further supported by the result presented in Fig. 3A, which shows that the separation of a mixture of DNA markers V and VI using the PEO-PVP-PEO(GNP) chip (75- $\mu \mathrm{m}$ channel) was not quite successful. Our reasoning is further supported by a relatively worse resolution of the DNA using a PEO-PVP-PEO(GNP) PMMA 

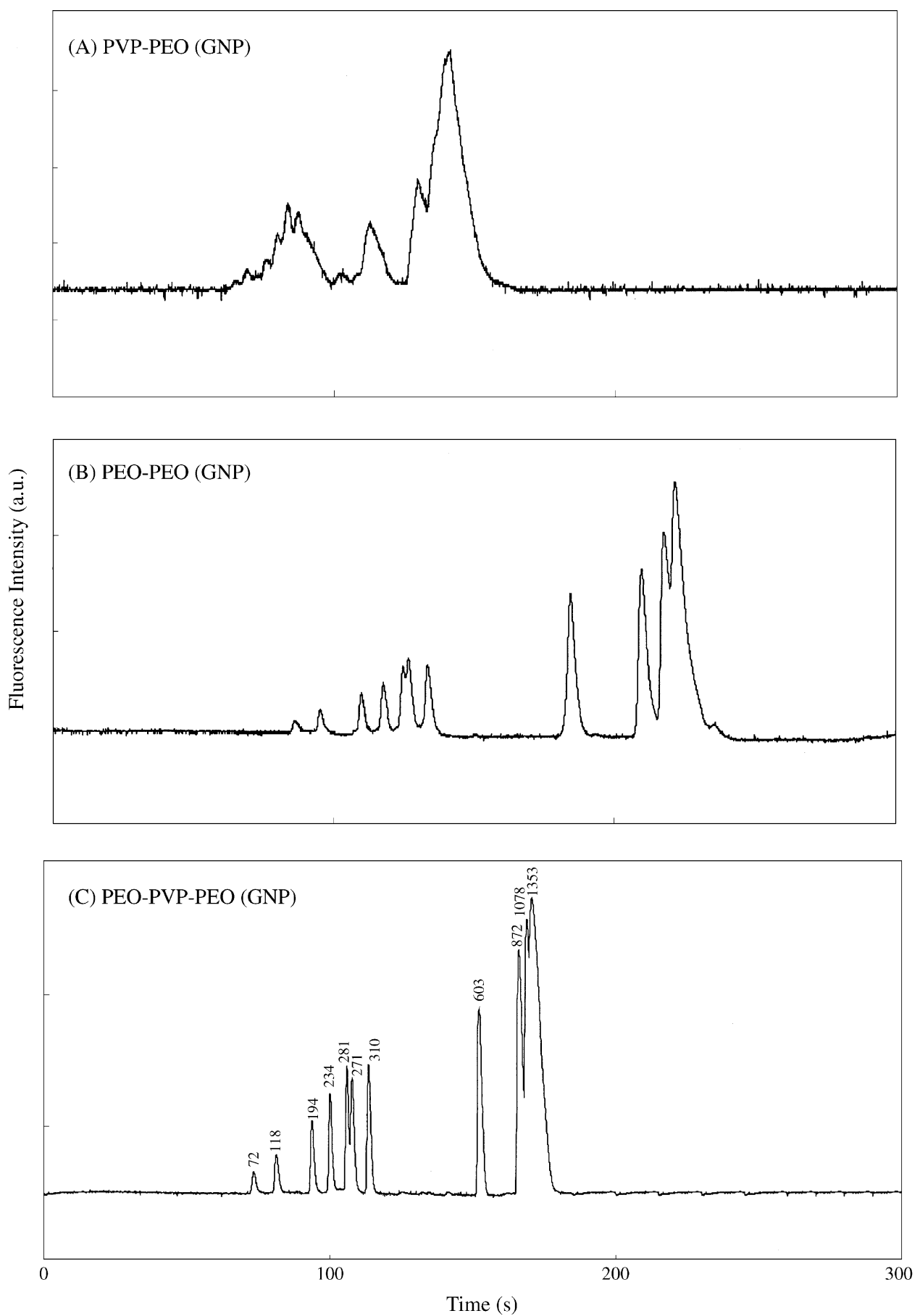

Fig. 2. Comparison of the separation of $10 \mu \mathrm{g} / \mathrm{mL}$ ФX 174 RF DNA-HaeIII digest using three differently coated PMMA chips. The $0.75 \%$ PEO(GNPs) was prepared in $50 \mathrm{mM}$ glycine containing $2.5 \mu \mathrm{g} / \mathrm{mL} \mathrm{EtBr}$, pH 9.1. The numbers in the electropherograms denote the DNA sizes (bp). Injection and separation voltages were as shown in Fig. 1B.Arbitrary unit was denoted by a.u.

chip with a channel size of $50 \mu \mathrm{m} \times 50 \mu \mathrm{m}$. A poor resolution is because DNA is relatively accessible to the wall and interacts with PMMA wall in a small channel if the coating is not completed. To further improve the resolving power by suppressing DNA adsorption, we fabricated $X$ (PEO-PVP)-PEO(GNP) PMMA chips, in which $X=2-10$. Fig. 3B and $\mathrm{C}$ show two representative electropherograms, using $X$-(PEO-PVP)-PEO(GNP) PMMA chips, where $X=2$ and 5, respectively. The two electropherograms both present significant improvements in resolution and speed when compared to those using a PVP-PEO-GNP PMMA chip [24]. The separation is highly efficient (up to $1.7 \times 10^{6}$ plates $/ \mathrm{m}$ ) when using the 2-(PEO-PVP)-PEO(GNP) PMMA chips. One reason for faster separation results obtained in this study 
Table 1

Comparison of the theoretical plates $(N)$ and resolution $(R)$ using different PMMA chips

\begin{tabular}{|c|c|c|c|c|c|c|c|c|}
\hline \multirow[t]{3}{*}{ DNA (bp) } & \multicolumn{2}{|l|}{$\mathrm{A}^{\mathrm{a}}$} & \multicolumn{2}{|l|}{$\mathrm{B}^{\mathrm{a}}$} & \multicolumn{4}{|l|}{$\mathrm{C}^{\mathrm{a}}$} \\
\hline & \multirow[t]{2}{*}{$N^{\mathrm{b}}\left(\times 10^{4}\right)$} & \multirow[t]{2}{*}{$R^{\mathrm{c}}$} & \multirow[t]{2}{*}{$N\left(\times 10^{5}\right)$} & \multirow[t]{2}{*}{$R$} & \multicolumn{2}{|l|}{ GNPs } & \multicolumn{2}{|l|}{ No GNPs ${ }^{d}$} \\
\hline & & & & & $N\left(\times 10^{5}\right)$ & $R$ & $N\left(\times 10^{5}\right)$ & $R$ \\
\hline $51(/ 72)$ & 9.7 & 0.7 & 1.8 & 1.8 & 3.0 & 1.8 & 1.3 & 1.5 \\
\hline $72(/ 118)$ & 7.0 & 1.1 & 2.5 & 2.7 & 4.0 & 3.7 & 1.6 & 2.5 \\
\hline $118(/ 197)$ & 7.5 & 0.3 & 1.8 & 1.3 & 3.0 & 2.4 & 2.1 & 1.3 \\
\hline $194(/ 281)$ & 3.0 & 0.4 & 2.3 & 1.3 & 14.0 & 2.5 & 2.4 & 1.0 \\
\hline $281(/ 271)$ & 3.3 & 0 & 3.5 & 0.4 & 15.0 & 1.2 & 1.1 & 0 \\
\hline 271(/310) & $\mathrm{ND}^{\mathrm{e}}$ & 0 & 2.5 & 1.3 & 7.0 & 1.7 & ND & 0 \\
\hline $310(/ 603)$ & 2.3 & 1.8 & 2.8 & 7.8 & 8.0 & 13 & 2.1 & 7.2 \\
\hline $603(/ 872)$ & 3.5 & 1.2 & 3.0 & 3.3 & 14.0 & 5.0 & 3.0 & 3.7 \\
\hline 872(/1078) & 4.3 & 0.4 & 6.8 & 0.8 & 17.0 & 0.6 & 4.0 & 0.2 \\
\hline $1078(/ 1353)$ & 2.8 & 0 & 2.5 & 0.5 & 4.0 & 0.3 & 1.3 & 0 \\
\hline 1353 & ND & - & 9.0 & - & 6.0 & 0 & ND & - \\
\hline Time window $(\mathrm{s})^{\mathrm{f}}$ & $66-141$ & & $87-221$ & & $73-170$ & & $92-242$ & \\
\hline
\end{tabular}

is that the electrophoretic mobility of DNA is greater in $0.75 \%$ PEO(GNP) solution (lower viscosity) than in $1.5 \%$ $\mathrm{PEO}(\mathrm{GNP})$. It is also interesting to note that the migration times slightly increased with increasing coating layers as a result of small EOF. With increasing the number of layers, greater coverage of the PMMA surface, leading to higher resolving power, and less negatively charged density (good coverage and greater amounts of PVP) in the surface, resulting in small EOF. In comparison of Fig. 3B and C, we realize that the 5-(PEO-PVP)-PEO(GNP) PMMA chip did not provide any significant advantages over 2-(PEO-PVP)-PEO(GNP) PMMA chip in terms of resolution and separation time. In contrast, the loss of resolution for small DNA fragments $(<298$ bp), a slightly higher fluorescence background, and a relatively unstable baseline are problematic when using the 5-(PEO-PVP)-PEO(GNP) PMMA chip. Similar problems were all found when using the $X$-(PEO-PVP)-PEO(GNP) PMMA chips, in which $X>4$.

To reveal the optical problems, we measured the UV-vis absorption of the $X$-(PEO-PVP)-PEO(GNP) PMMA plates. The UV-vis absorbance in the range of $300-900 \mathrm{~nm}$ (spectra a-h in Fig. 4) increases with increasing number of $X$ (sequence), indicating the formation of multilayer-coated PMMA plates. The increase in absorbance $(\mathrm{a}-\mathrm{g})$ is mainly due to increased thickness of the coating layer and the changes in refractive index of the surface, while the increases in absorbance between $\mathrm{g}$ and $\mathrm{h}$ is also due to the presence of GNP that possesses a greater absorption extinction coefficient $\left(\varepsilon \sim 10^{10} \mathrm{~cm}^{-1} \mathrm{M}^{-1}\right.$ at $\left.\lambda=532 \mathrm{~nm}\right)$ than do PEO and PVP in the visible range. The increase in absorbance $(\mathrm{a}-\mathrm{g})$ is not proportional to the number of layers, suggesting that the thickness of each layer is not always the same. The result partially explain why reproducibility for the DNA separa- tion is relatively poor when using $X$-(PEO-PVP)-PEO(GNP) PMMA chips, in which $X>3$. Increases in absorbance (thickness of coating layer) support that a higher fluorescence background observed in Fig. $3 \mathrm{C}$ is mainly due to scattering. We point out that similar UV-vis absorption measurements (not shown) revealed that multilayer-coated PMMA plates did not form if there was no PVP coating between $\operatorname{PEO}\left(6.0 \times 10^{5} \mathrm{~g} / \mathrm{mol}\right)$ and $\mathrm{PEO}\left(8.0 \times 10^{6} \mathrm{~g} / \mathrm{mol}\right)$ coatings. This is because of strong interactions between two different sizes of PEO molecules. Owing to lack of forming multilayer coating, the loss of resolution and irreproducibility for DNA separation is problematic when using $X$ - $[\mathrm{PEO}(6.0$ $\left.\left.\times 10^{5} \mathrm{~g} / \mathrm{mol}\right)-\mathrm{PEO}\left(8.0 \times 10^{6} \mathrm{~g} / \mathrm{mol}\right)\right]-\mathrm{PEO}(\mathrm{GNP})$ PMMA chips or $X$-[PEO-PEO(GNP)] PMMA chips.

\subsection{Advantage and reproducibility}

There are several advantages of conducting DNA separation by MCE using 2-(PEO-PVP)-PEO(GNP) PMMA chips . Low-viscosity PEO(GNP) can be used as a sieving matrix, allowing one easily to fill and replace the sieving matrix by syringe suction. This simplifies our MCE system because a high pressure means for filling high-viscosity $\mathrm{PEO}(\mathrm{GNP})$ and PEO solutions to microchannels is no longer needed. Deterioration of the coating due to high pressure is prevented. As a result, the chip can be reused for more than 30 runs after simple filling of the channel with fresh PEO(GNP). The chip can be used for more than 3 months if the microchannel is filled with PEO(GNPs) and the chip is sealed and stored in refrigerator at $4{ }^{\circ} \mathrm{C}$. The relative standard deviation (R.S.D.) for the migration time is less than $1.3 \%$ for five consecutive runs. It is important to note that the R.S.D. is about $2.7 \%$ when $0.75 \%$ PEO(GNP) was used for four consecutive runs 

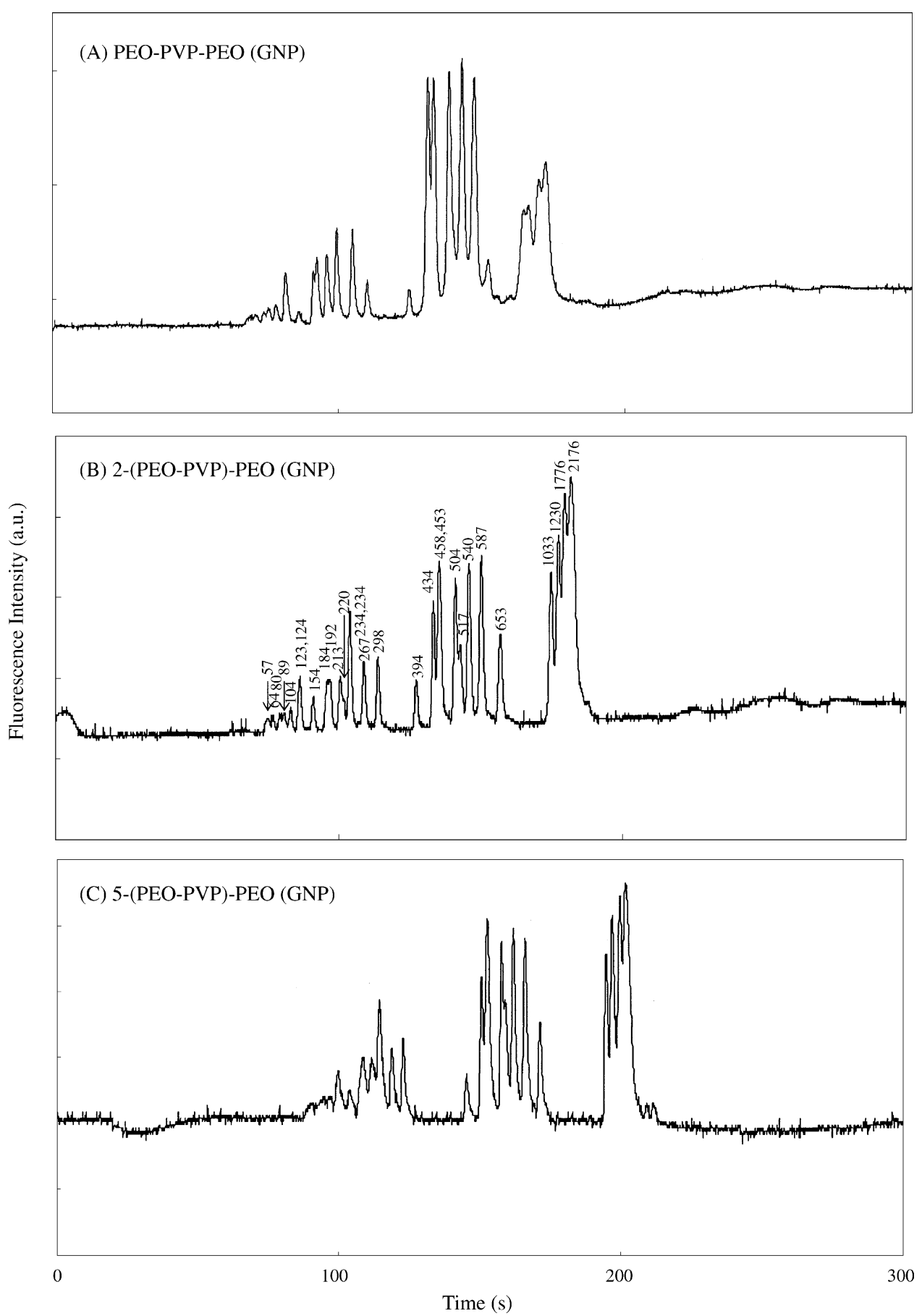

Fig. 3. Separations of a mixture containing $2.5 \mu \mathrm{g} / \mathrm{mL}$ DNA markers V and VI using $X$-(PEO-PVP)-PEO(GNP) PMMA chips. Other conditions were the same as in Fig. 2.

(without refilling). Although Fig. 4 reveals that the variation of coating occurred among different layers, the chip-to-chip reproducibility is less than $3.0 \%$.

\subsection{Separation of PCR products}

Antibiotic treatment varies according to the species of mycobacteria [40,41]. Therefore, it is particularly important to diagnose Mycobacterium species as rapidly as possible. Traditional identification method of tuberculosis used to take several weeks because of the slow growth rate of mycobacteria and a slow separation process of slab gel electrophoresis [42]. Recently, integrated microfluidic devices that incorporate with sample preparation, PCR, and CE separation in a small chip have been applied to many fields such as diagnoses, forensics, and so on $[1,6,43]$. To test the potential of 


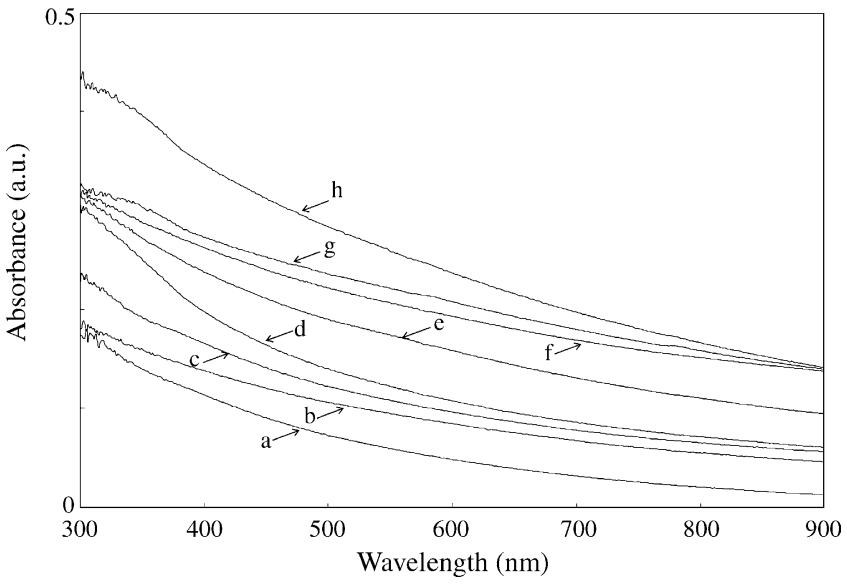

Fig. 4. UV-vis spectra for $X$-(PEO-PVP)-PEO(GNP) PMMA plates. Spectra a-h were for the plates with $X=1-10$, respectively. Absorbance unit was denoted by a.u.

the 2-(PEO-PVP)-PEO(GNP) PMMA chip for diagnostic purposes, the $h s p 65$ gene fragments of Mycobacterium after HaeIII digestion were tested. Fig. 5 shows that the separation of the digested PCR products (21-152 bp) was accomplished in 90 s. The R.S.D. values $(n=3)$ of the migration times for all the fragments are all less than $1.5 \%$, showing good reproducibility of this method. We note that the chip was used for more than 30 runs, without degradation. The chip-to-chip reproducibility is also reasonable (R.S.D. < 4.6\%). A greater R.S.D. value compared to those obtained in separating standard DNA markers is because the PCR sample was prepared in a much higher concentration salt media. The result indicates the possibility of rapidly detecting different species of mycobacteria from a greater number of samples if a multiplexed system in a microchip format is applied. Although the integration of a chip system has not been developed in this lab yet, the result shows potential of the 2-(PEO-PVP)-PEO(GNP) PMMA chip for identification of a numbers of species of mycobacteria, in an inexpensive cost.

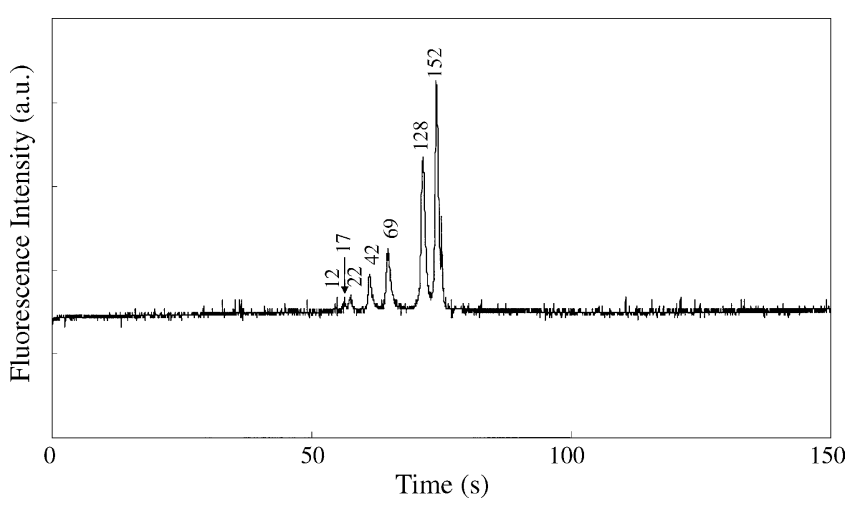

Fig. 5. Separation of hsp65 gene fragments of Mycobacterium HaeIII digests. Other conditions were as the same as in Fig. 3B.

\section{Conclusions}

The progress in conducting dynamic coating of the separation channels fabricated on PMMA chips is described. To prevent DNA adsorption on the channel wall of PMMA chips, it is important to coat the separation channel with small sizes of PEO molecules. In order to form multilayer coating of PMMA chips, PVP coating is required between PEO and PEO(GNPs). Using a 2-(PEO-PVP)-PEO(GNP) PMMA chip, the separation of DNA markers V and VI by MCE using $0.75 \%$ PEO(GNP) was accomplished in $3 \mathrm{~min}$. The separation of hsp65 gene fragments of Mycobacterium Hae III digests was completed in $90 \mathrm{~s}$, showing the potential of this technique for diagnosis of Mycobacterium species. Owing to a low viscosity of $0.75 \% \mathrm{PEO}(\mathrm{GNP})$ solution, filling the microchannels is no longer a problem. As a result, small channels (e.g. $25 \mu \mathrm{m}$ ) might be used to further improved resolution if needed.

\section{Acknowledgements}

This work was supported by the National Science Council of Taiwan under contract numbers NSC 92-2113-M-002048 and NSC 92-2120-M-002-028, as well as the Center for Nano Science and Technology, National Taiwan University. We thank C.-C. Hung and P.-L. Chang for preparing the PCR products.

\section{References}

[1] J.P. Landers, Anal. Chem. 75 (2003) 2919.

[2] I.L. Medintz, B.M. Paegel, R.G. Blazej, C.A. Emrich, L. Berti, J.R. Scherer, R.A. Mathies, Electrophoresis 22 (2001) 3845.

[3] M.F. Fey, Lancet Oncol. 3 (2002) 349

[4] T. Tang, M.Y. Badal, G. Ocvirk, W.E. Lee, D.E. Bader, F. Bekkaoui, D.J. Harrison, Anal. Chem. 74 (2002) 725.

[5] C.A. Emrich, H. Tian, I.L. Medintz, R.A. Mathies, Anal. Chem. 74 (2002) 5076.

[6] J. Khandurina, T.E. McKnight, S.C. Jacobson, L.C. Waters, R.S. Foote, J.M. Ramsey, Anal. Chem. 72 (2000) 2995.

[7] Y. Shi, R.C. Anderson, Electrophoresis 24 (2003) 3371.

[8] O. Mueller, K. Hahnenberger, M. Dittmann, H. Yee, R. Dubrow, R. Nagle, D. Ilsley, Electrophoresis 21 (2000) 128.

[9] M. Ueda, Y. Kiba, H. Abe, A. Arai, H. Nakanishi, Y. Baba, Electrophoresis 21 (2000) 176.

[10] L. Zhang, F. Dang, Y. Baba, Electrophoresis 23 (2002) 2341.

[11] Z. Ronai, C. Barta, M. Sasvari-Szekely, A. Guttman, Electrophoresis 22 (2001) 294.

[12] W.-L. Tseng, Y.-W. Lin, K.-C. Chen, H.-T. Chang, Electrophoresis 23 (2002) 2477.

[13] H. Wang, J. Qin, Z. Dai, L. Wang, J. Bai, B. Lin, J. Sep. Sci. 26 (2003) 869

[14] Z. Huang, J.C. Sanders, C. Dunsmor, H. Ahmadzadeh, J.P. Landers, Electrophoresis 22 (2001) 3924

[15] N. Kaji, Y. Tezuka, Y. Takamura, M. Ueda, T. Nishimoto, H. Nakanishi, Y. Horiike, Y. Baba, Anal. Chem. 76 (2004) 15.

[16] J.W. Hong, K. Hosokawa, T. Fujii, M. Seki, I. Endo, Biotechnol. Prog. 17 (2001) 958. 
[17] Y. Liu, D. Ganser, A. Schneider, R. Liu, P. Grodzinski, N. Kroutchinina, Anal. Chem. 73 (2001) 4196.

[18] Y.-H. Chen, S.-H. Chen, Electrophoresis 21 (2000) 165.

[19] M.A. Roberts, J.S. Rossier, P. Bercier, H. Girault, Anal. Chem. 69 (1997) 2035.

[20] J. Rossier, F. Reymond, P.E. Michel, Electrophoresis 23 (2002) 858.

[21] H. Becker, L.E. Locascio, Talanta 56 (2002) 267.

[22] D. Belder, M. Ludwig, Electrophoresis 24 (2003) 3595.

[23] S.A. Soper, A.C. Henry, B. Vaidya, M. Galloway, M. Wabuyele, R.L. McCarley, Anal. Chim. Acta 470 (2002) 89.

[24] Y.-W. Lin, M.-J. Huang, H.-T. Chang, J. Chromatogr. A 1014 (2003) 47.

[25] F. Xu, M. Jabasini, Y. BaBa, Electrophoresis 23 (2002) 3608.

[26] C.-C. Huang, Y.-F. Huang, H.-T. Chang, Nanosci, Nanotechnol. 4 (2003) 1.

[27] M.-F. Huang, C.-C. Huang, H.-T. Chang, Electrophoresis 24 (2003) 2896.

[28] G. Frens, Nature 241 (1973) 20.

[29] N.R. Jana, L. Gearheart, C.J. Murphy, Langmuir 17 (2001) 6782.

[30] L. Martynova, L.E. Locascio, M. Gaitan, G.W. Kramer, R.G. Christensen, W.A. MacCrehan, Anal. Chem. 69 (1997) 4783.

[31] T. Schinnick, J. Bacteriol. 169 (1987) 1080.
[32] P.G. Righetti, C. Gelfi, B. Verzola, L. Castelletti, Electrophoresis 22 (2001) 603.

[33] A.C. Henry, T.J. Tutt, M. Galloway, Y.Y. Davidson, C.S. McWhorter, S.A. Soper, R.L. McCarley, Anal. Chem. 72 (2000) 5331.

[34] J.E. Melanson, N.E. Baryla, C.A. Lucy, Anal. Chem. 72 (2000) 4110.

[35] S.L.R. Barker, M.J. Tarlov, H. Canavan, J.J. Hickman, L.E. Locascio, Anal. Chem. 72 (2000) 4899.

[36] J. Horvath, V. Dolník, Electrophoresis 22 (2001) 644.

[37] B. Verzola, C. Gelfi, P.G. Righetti, J. Chromatogr. A 868 (2000) 85.

[38] M. Galloway, W. Stryjewski, A. Henry, S.M. Ford, S. Llopis, R.L. McCarley, S.A. Soper, Anal. Chem. 74 (2002) 2407.

[39] S.-J. Wang, W.-L. Tseng, Y.-W. Lin, H.-T. Chang, J. Chromatogr. A 979 (2002) 261.

[40] A. Troesch, H. Nguyen, C.G. Miyada, S. Desvarenne, T.R. Gingeras, P.M. Kaplan, P. Cros, C. Mabilat, J. Clin. Microbiol. 37 (1999) 49.

[41] M.A. Yakrus, S.M. Hernandez, M.M. Floyd, D. Sikes, W.R. Butler, B. Metchock, J. Clin. Microbiol. 39 (2001) 4103.

[42] F. Brunello, M. Ligozzi, E. Cristelli, S. Bonora, E. Tortoli, R. Fontana, J. Clin. Microbiol. 39 (2001) 2799.

[43] M.C. Breadmore, K.A. Wolfe, I.G. Arcibal, W.K. Leung, D. Dickson, B.C. Giordano, M.E. Power, J.P. Ferrance, S.H. Feldman, P.M. Norris, J.P. Landers, Anal. Chem. 75 (2003) 1880. 